\title{
Territorialidades y representaciones sociales superpuestas en la dicotomía agua vs. oro: el conflicto socioambiental por minería industrial en el páramo de Santurbán *
}

Territorialities and Social Representations Superimposed on the Water vs. Gold Dichotomy: The Socio-Environmental Conflict over Industrial Mining in the Santurban Moorland

Territorialidades e representações sociais sobrepostas na dicotomia água vs. ouro: o conflito socioambiental por mineração industrial no páramo de Santurbán

Raquel Méndez Villamizar ${ }^{* *}$ Andrea Mejía Jerez ${ }^{* * *}$ Álvaro Acevedo Tarazona ${ }^{* \star * *}$

Recibido: 10 de enero de 2019

Aprobado: 10 de octubre de 2019

Doi: https://www.doi.org/10.12804/revistas.urosario.edu.co/territorios/a.7563

Para citar este artículo:

Méndez Villamizar, R., Mejía Jerez, A., \& Acevedo Tarazona, Á. (2020). Territorialidades y representaciones sociales superpuestas en la dicotomía agua vs. oro: El conflicto socioambiental por minería industrial en el páramo de Santurbán. Territorios, (42-Especial), 1-25. https://www.doi.org/10.12804/revistas.urosario. edu.co/territorios/a.7563

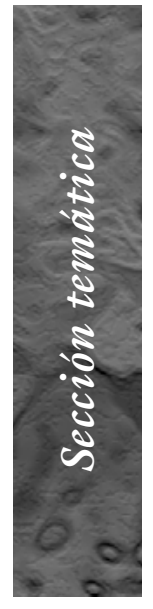

* Artículo derivado de los proyectos de investigación: La participación de las mujeres en acciones colectivas socio-ambientales: $E l$ caso de minería industrial en el Páramo de Santurbán durante el año 2011, código VIE-UIS: 2329 y el proyecto El páramo de Santurbán y los derechos de sus pobladores en un contexto de conservación ambiental del entorno, código VIE-UIS: 1969, ambos financiados por la Vicerrectoría de Investigación y Extensión de la Universidad Industrial de Santander.

** Profesora titular de la Universidad Industrial de Santander (Colombia). Correo electrónico: rmendezv@uis.edu.co. ORCID: 0000-0003-1005-5809

*** Trabajadora social. Universidad Industrial de Santander $\Longrightarrow$ 
Palabras clave

Territorio, representaciones sociales, agua, oro, conflicto socioambiental, minería, páramo.

Keywords

Territory, social representations, water, gold, socio-environmental conflict, mining, moorland.

Palavras-chave

Território, representações sociais, água; ouro, conflito socioambiental, mineração, páramo.

\section{tersitarios 42-Especial}

RESUMEN

El páramo de Santurbán (Colombia) es un espacio biogeográfico y biodiverso, y centro de disputas sociales, políticas y económicas. Este artículo analiza las representaciones del agua, el oro y la superposición de las territorialidades de distintos grupos sociales en el año 2011 como efecto del conflicto socioambiental por minería industrial. Para ello se realizó un ejercicio de interpretación narrativa de entrevistas semiestructuradas a pobladores y colectivos sociales de los municipios de Vetas y California y de la ciudad de Bucaramanga, quienes argumentaron sobre la importancia del agua y del oro en su vida cotidiana. La población de Santurbán concibe el agua como fundamental para su existencia y al oro, para su economía, las tradiciones y la cultura. Mientras tanto, para la población de Bucaramanga, la representación del agua se relaciona con la ética ambientalista. Esta superposición desencadena conflictos antes invisibilizados entre dos poblaciones vecinas que se han beneficiado del páramo conjuntamente.

\section{ABSTRACT}

The Santurban moorland (Colombia) is a biogeographic space with mining, water, and biodiverse potential, which forms a framework of social, political, and economic disputes. This article analyzes the representations of water and gold, and the superposition of the territorialities of the different social groups (Santurban population, Bucaramanga population, foreign company, and State) in 2011 as an effect of the socio-environmental conflict over industrial mining in the moor. To do this, the researchers carried out an exercise in narrative interpretation of semistructured interviews with residents and social groups in the municipalities of Vetas, California, and the city of Bucaramanga, who argue the importance of water and gold in their daily lives. The population of Santurbán conceives water as fundamental for its existence and the gold for its economy, traditions, and culture. Meanwhile, for the population of Bucaramanga, the representation of water is related to environmental ethics. This overlap triggers previously invisible conflicts between two neighboring populations that have jointly benefited from the moorland.

\section{RESUMO}

O páramo de Santurbán (Colômbia) é um espaço biogeográfico e biodiverso, centro de disputas sociais, políticas e econômicas. Este artigo analisa as representações da água, o ouro e a sobreposição das territorialidades de distintos grupos sociais no ano 2011 como efeito do conflito socioambiental por mineração industrial. Para isto, realiza um exercício de interpretação narrativa de entrevistas semiestruturadas a habitantes e coletivos sociais dos municípios de Vetas, Califórnia e a cidade de Bucaramanga, quem argumentam a importância da água e do ouro em sua vida cotidiana. A população de Santurbán concebe a água fundamental para sua existência e o ouro para sua economia, as tradições e a cultura. Entretanto, para a população de Bucaramanga, a representação da água se relaciona com a ética ambientalista. Esta sobreposição desencadeia conflitos antes invisibilizados entre duas populações vizinhas que se têm beneficiado do páramo conjuntamente. 


\section{Introducción}

El páramo de Santurbán está situado en los departamentos de Santander y Norte de Santander. Su extensión es de 142000 hectáreas. En Santander la extensión del páramo se ubica principalmente en la provincia de Soto Norte, la cual está compuesta por los municipios de California, Charta, Suratá, Tona y Vetas. En los municipios auríferos de California y Vetas se presenta una realidad compleja. Desde 1994 hay presencia de empresas mineras extranjeras y desde 2009 hay una tensión latente por los proyectos de explotación de oro a gran escala propuestos por estas. El 2011 es un punto de partida para el conflicto socioambiental, pues la empresa canadiense Greystar, con su intención de explotar el páramo a cielo abierto, alertó a la ciudadanía y apresuró la necesidad de organizarse para defender el agua y el territorio. Desde ese momento, la empresa de extracción minera desencadenó un conflicto socioambiental entre la población "ambientalista" (de Bucaramanga y en menor medida de Santurbán), los pobladores del páramo estigmatizados por ser mineros y el Estado. Dicho conflicto gira en torno a la dualidad: "agua vs. oro". Esta dualidad presenta una disyuntiva muy peculiar de la cual surge una aparente oposición, pero los hallazgos de esta investigación invitan a mirar el conflicto socioambiental desde una perspectiva más compleja.

Si bien el agua es parte de las formas de vida sociales, biológicas y antropológicas y se configura como un derecho humano, ${ }^{1}$ su caracterización cambiante se comporta de manera particular en la lógica productiva del mundo contemporáneo. Lo mismo sucede con el oro, aunque este recurso configura las costumbres y tradiciones de gran parte de la población de Soto Norte, es un elemento con gran valor económico que moviliza los intereses del mercado mundial. El conflicto que se configuró por el juego de tensiones entre distintos actores (Estado, empresas transnacionales, grupos ambientalistas y mineros tradicionales de Soto Norte) mantiene la dualidad inicialmente mencionada, pero olvida otros aspectos que también la afectan.

Este artículo pretende analizar las representaciones del agua y el oro y la superposición de territorialidades de los distintos grupos sociales (población de Santurbán, población de Bucaramanga, empresa extranjera y Estado) en el año 2011 como efecto del conflicto socioambiental por minería industrial en el páramo de Santurbán. En consecuencia, el texto se divide en cuatro apartados. En primera medida se realiza una lectura conceptual de los conflictos socioambientales, las territorialidades y las representaciones sociales. Como segundo punto se desarrolla la discusión sobre el conflicto socioambiental que se configuró en torno al páramo de Santurbán durante el año 2011, que afectó la forma de vida de las poblaciones y su relación con el territorio. En un tercer momento se analizan las transformaciones en las territorialidades y

nico: andreamejia2122@ gmail.com. ORCID: 0000-0002-1051-5812

**** Profesor titular de la Universidad Industrial de Santander (Colombia). Director del grupo Politicas, Sociabilidades y Representaciones Histórico-Educativas. Correo electrónico: acetara@uis. edu.co. ORCID: 0000-00023563-9213

${ }^{1}$ El agua como recurso ba sido caracterizada desde diferentes perspectivas como bien público, económico y común. Desde los años ochenta, la imposición del modelo económico neoliberal supuso la privatización de los bienes y servicios públicos como el agua. Esta perspectiva quedó plasmada en la Declaración de Dublin sobre Agua y Desarrollo Sostenible de 1992, en la que se reconoce que el agua constituye un bien económico. Frente a la lógica del mercado, los movimientos sociales reivindican el reconocimiento del acceso al agua $y$ al saneamiento como un derecho humano, cuya satisfacción debe gestionarse como un servicio público. Ello supone la consideración del agua como bien común. En 2002, el Comité

\section{territarios} 42-Especial 
$\Leftarrow$

de Derechos Económicos, Sociales y Culturales de Naciones Unidas, mediante su Observación General 15, reconoció que el derecho al agua es indispensable para vivir dignamente y es condición previa para la realización de otros derechos humanos; asume, además, que constituye un recurso natural limitado y un bien público fundamental para la vida y la salud. El 28 de julio de 2010, la Asamblea General de Naciones Unidas aprobó la Resolución 64/292, en la que reconoce el derecho humano al agua potable y el saneamiento, reafirmando que este es legalmente vinculante para los Estados toda vez que se deriva del derecho al más alto nivel posible de salud física y mental, así como al derecho a la vida y dignidad humana. Además, en abril de 2011, el Consejo de Derechos Humanos reconoce, mediante su Resolución 16/2, el acceso seguro al agua potable $y$ al saneamiento como un derecho bumano: derecho a la vida y a la dignidad humana (bttps:// www.ecologistasenaccion. org/22493/el-bien-comunel-derecho-bumano-alagua-y-las-politicas-deprivatizacion/).

\section{territarios 42-Especial}

las representaciones del agua y el oro de los distintos actores a partir del conflicto socioambiental. Para finalizar, se presentan unas conclusiones y reflexiones en torno a la problemática planteada; así mismo, se enfatiza en el deber de la academia de construir conocimiento en esta temática, necesario para afrontar el futuro del país y de la región.

\section{Metodología}

Para responder al objetivo de este artículo, se optó por una metodología cualitativa de interpretación narrativa, apoyada en el contraste de datos empíricos recolectados en entrevistas semiestructuradas. Estas se aplicaron a cuatro activistas del movimiento ambientalista en el Área Metropolitana de Bucaramanga, de los cuales tres son hombres mayores de 50 años y una es mujer entre los 20 y los 30 años de edad. También se aplicó la entrevista a seis líderes sociales del municipio de California, Santander, ubicado en el Páramo de Santurbán, de los cuales tres son hombres entre los 20 y los 50 años de edad; las otras tres personas son mujeres, las cuales se encuentran en el rango de edad de los 30 a los 70 años. Adicional a ello, se entrevistó a un experto en la problemática, quien no pertenece a ninguno de los grupos sociales mencionados anteriormente, pero analiza el tema desde una perspectiva histórica y aporta a la producción científica respecto a los conflictos socioambientales por minería aurífera en Colombia. Todas las personas entrevistadas vivieron de manera cercana el conflicto en torno al páramo de Santurbán durante el año 2011 frente a las intenciones extractivas de la empresa canadiense Greystar.

\section{Aproximación teórica: territorialidades, representaciones y conflictos socioambientales}

La investigación social se ha preocupado por estudiar diversos tipos de conflictos que surgen por la tensión entre distintas posturas sobre el control, acceso, uso y conservación de territorios ricos en recursos naturales, mediante los cuales se logran avances científicos, técnicos, tecnológicos, económicos, sociales, etc. Pero la forma en la que estos recursos son utilizados genera conflictos que marcan la historia de las poblaciones ricas en biodiversidad y recursos como el agua, el oro y el petróleo, entre otros.

Según Torres (2005), los conflictos socioambientales se generan entre actores sociales movilizados por intereses diversos alrededor de los recursos naturales. Las disputas por la hegemonía de los territorios a distintos niveles movilizan modos de apropiación que desempeñan un papel central en la constitución de las territorialidades de los distintos actores que sostienen los conflictos. Uno de los desafíos más frecuentes en la actualidad es la conflictividad que suge al tratar de preservar los ecosistemas al tiempo que se impulsa el desarrollo en un modelo 
económico que privilegia los proyectos industriales de explotación ambiental como el extractivismo. La economía extractivista consiste en la explotación y exportación de recursos primarios, que implica una elevada demanda de capital y tecnología que funciona con una lógica de enclave, es decir, las empresas transnacionales localizan sus actividades productivas sin una propuesta integradora de esas actividades primario-exportadoras a la economía local, dejando a esta última sujeta a las vicisitudes del mercado mundial. En especial, queda vulnerable a la competencia de otros países en similares condiciones (Acosta, 2009, pp. 28-29). Si bien esta actividad ha acompañado la historia de los países latinoamericanos desde hace varios siglos, en décadas recientes ha adquirido nuevas dimensiones en cuanto al grado de devastación ambiental, los volúmenes extraídos y las técnicas de alta intensidad sobre los territorios (Gudynas, 2015).

El extractivismo hoy en día (...) es pensado como la opción más rápida para el desarrollo de los países de la región, incluida Colombia (...) Diversas formas de extractivismo han desencadenado múltiples conflictos por procesos de desterritorialización y desarraigo, rupturas en las relaciones del ser humano con el entorno, y violencia epistémica, étnica y de género, entre otros, que han fracturado a las comunidades, afectadas de este modo en sus espacios de vida y en las formas como habitan, viven y producen el territorio (Ulloa \& Coronado, 2016).
René Orellana (1999a, p. 101) identifica en sus investigaciones dos formas de entender los recursos de la naturaleza, que determinan el modo como las partes se surten de sus beneficios: 1) La naturaleza entendida como recurso natural. Esta postura entiende que el medio ambiente es un bien del ser humano que puede ser aprovechado y utilizado para su propio beneficio; esta suele ser la postura de las empresas extractoras de recursos y de los gobiernos que buscan posicionarse en los índices de desarrollo social. 2) La que la entiende como un espacio de vida en torno al cual las poblaciones construyen significados, culturas y mantienen una interacción constante con el ambiente.

Las representaciones sociales en torno al agua y al oro sirven para entender el sentido que otorgan los actores sociales al medio ambiente y la importancia que dan al uso y aprovechamiento de la naturaleza de Santurbán. Estas representaciones individuales y colectivas fundamentan la aceptación o el rechazo de proyectos político-culturales y económicos que afectan el territorio y las territorialidades construidas en él, por ejemplo, los proyectos extractivistas. Los sujetos son agentes actuantes y pensantes, dotados de un sentido práctico que orienta la percepción de los acontecimientos. La representación social no se produce solo en la interpretación de la realidad, sino que implica también involucrarse de forma práctica, teniendo en cuenta que existe un contexto con unos límites, es decir, los significados asignados tersitarios 42-Especial 
dependen de los recursos económicos, sociales, culturales y simbólicos disponibles (Bourdieu \& Wacquant, 1995, p. 40).

Las representaciones sociales son elementos centrales para entender los procesos de construcción de las territorialidades. La territorialidad constituye la relación dinámica entre los componentes sociales (economía, cultura, instituciones, poder) y aquello material e inmaterial que es propio del territorio (Dematteis \& Governa, 2005 , p. 33). También puede ser entendida como la mediación simbólica, cognoscitiva y práctica que la materialidad de los lugares ejerce sobre el comportamiento social (Raffestin, 2011). Esta también se manifiesta en la apropiación simbólica del espacio y en la historia de vida de las personas, la cual a su vez involucra lazos emocionales con el territorio (Franky \& Mahecha, 2000, p. 199). Este concepto se adapta de acuerdo a las dinámicas ambientales, económicas, políticas y culturales de la sociedad. Es decir, la territorialidad no es única y constante, sino que depende de las experiencias y las interpretaciones de quienes la construyen. Es por esto que las territorialidades no son homogéneas ni pueden ser explicadas de forma jerárquica, sino que son diversas, toda vez que quienes interactúan con el territorio configuran una forma diferente de entenderlo, es decir, múltiples territorialidades. Como afirman Guattari y Rolnik (2006):
El territorio puede ser relativo tanto a un espacio vivido como a un sistema percibido dentro del cual un sujeto se siente "una cosa”. El territorio es sinónimo de apropiación, de subjetivación fichada sobre sí misma. Él es un conjunto de representaciones las cuales van a desembocar, pragmáticamente, en una serie de comportamientos, inversiones, en tiempos y espacios sociales, culturales y cognitivos (p. 323).

De acuerdo con Rodríguez (2010), la territorialidad se configura como pertenencia territorial supeditada a procesos de identificación y de representación colectiva e individual. La construcción del territorio, al ser social, es diversa, depende de los esquemas mentales y corporales, así como de la matriz simbólica que permite la apropiación de los recursos materiales y de las representaciones sociales construidas en torno a ellos. Por esto, es importante dialogar con el concepto de territorialidad, pues desde allí es posible encontrar las herramientas teóricas para entender los conflictos socioambientales, donde se implican no solo las poblaciones que habitan la zona de influencia, o las empresas transnacionales, sino también los movimientos ambientales que se oponen rotundamente al extractivismo industrial que, sin habitar el territorio, también tienen una relación importante con él.

En resumen, toda relación social ocurre en el territorio y se expresa como territorialidad. En el espacio ocurren y 
se sobreponen distintas territorialidades locales, regionales, nacionales y mundiales con intereses y percepciones distintas que generan relaciones de complementación, cooperación y conflicto. En un mismo espacio se sobreponen múltiples territorialidades (Montañez \& Delgado, 1998, p. 123). Cuando estas se encuentran en desacuerdo o se sobreponen es común que se generen conflictos socioambientales. René Orellana (1999a, p. 101) los distingue así: 1) los conflictos internos de quienes ven la naturaleza como recurso: estos conflictos se refieren al uso, acceso, explotación y manejo de los recursos; son los conflictos que pueden surgir entre el Estado y las empresas extractoras o incluso entre las mismas empresas; 2) los conflictos internos de quienes ven la naturaleza como espacio de vida: estos se dan por el uso, acceso y manejo de los espacios. Aquí se encuentran los conflictos interétnicos e intercomunitarios, entre otros. Los conflictos que se producen en la defensa del territorio están entrecruzados por lecturas diversas, muchas veces encontradas y otras veces contradictorias sobre lo que se espera de los recursos que este provee. "Hay acuerdo sobre el hecho de que el conflicto es una forma de interacción entre individuos, grupos, organizaciones y colectividades que implica enfrentamientos por el acceso a recursos escasos y su distribución" (Bobbio, Matteucci \& Pasquino, 1991, p. 298).

Los conflictos socioambientales dependen de la relación que tienen los actores sociales con la naturaleza, pero también con el territorio. En estos contextos, las tensiones entre diferentes territorialidades remiten con frecuencia a un enfrentamiento entre lo local y las intervenciones "externas" que amenazan el espacio geográfico. Las territorialidades y representaciones sociales son elementos que relacionan históricamente el extractivismo minero con los conflictos socioambientales en un contexto de cambios a raíz de la aparición de la minería a gran escala en 2011. El territorio, estudiado como un espacio que está determinado por las relaciones sociales y de poder que lo producen y mantienen, puede crear relaciones socioambientales conflictivas que construyen "territorialidades superpuestas" (Fernández, 2005; Quiroga, 2016, p. 238). Estas superposiciones llevan a la organización social y a las acciones colectivas, las cuales se constituyen como una dinámica relacional entre los actores sociales. ${ }^{2}$ En Colombia, las acciones colectivas son bastante participativas, en especial desde los espacios cívicos. Estos últimos tienen entre sus preocupaciones, objetivos como la importancia de un ambiente sostenible (Castro-Gómez, 2015). El desarrollo económico de la región es un tema neurálgico de los conflictos, se hace urgente el diálogo ante la fricción entre la lucha por la preservación del medioambiente (derecho a un ambiente sano y protegido), pero también la garantía del mínimo vital (derecho al trabajo).
${ }^{2}$ Las acciones colectivas son entendidas aqui como las distintas formas de manifestación que se proponen congregar a las personas para posicionar socialmente una propuesta y una postura politica frente a una problemática. Los actores colectivos producen la acción colectiva porque son capaces de definirse a si mismos y al campo de su acción - relaciones con otros actores, disponibilidad de recursos, oportunidades, limitaciones- (Melucci, 2010).

\section{territarios 42-Especial}

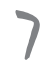


3 Ver: http://www. cdmb.gov.co/web/sitiosde-interes-ambientall parque-naturales-regionales/paramo-de-santurban

${ }^{4}$ Bucaramanga fue titulada Real de Minas: campamento donde residian mineros en 1622, con un Teniente de Alcalde, cura doctrinero, escribano y alguacil como autoridades. El Alcalde Mayor moraba por lo general en Las Vetas, razón por la cual Bucaramanga era administrada por un Teniente (Valderrama, 1948, p. 60).

5 «Los yacimientos de aluvión son aquellos que posterior a procesos de meteorización de un yacimiento primario hay una disgregación mecánica natural y por acción del agua las partículas de oro son transportadas a ciertas distancias estas tienden a concentrarse en cauces hidricos, dando lugar a los conocidos "placeres auriferos” [...] La explotación de oro de aluvión se encuentra en áreas de pendientes suaves y planas, generalmente en áreas de vegetación natural (bosques) aunque varia según la región; se observa una incipiente infraestructura vial, áreas pequeñas de

\section{territarios 42-Especial}

\section{El conflicto socioambiental por minería industrial en Santurbán (2011)}

La zona aurífera del páramo de Santurbán tiene una extensión aproximada de 80000 hectáreas, de las cuales cerca del $26 \%$ se ubica en el departamento de Santander, en los municipios de California, Charta, Suratá, Tona y $\operatorname{Vetas}^{3}$ (figura 1).

El extractivismo tiene una larga historia en el departamento. Se remonta a la conquista y fue el motor de la economía durante siglos. Como lo afirma el historiador y académico Armando Martínez en una entrevista realizada para las investigaciones que originaron este artículo: "esta ciudad [Bucaramanga] existe gracias al oro (...) Bucaramanga fue hasta la independencia un Real de Minas, ${ }^{4}$ con un alcalde mayor de minas, y existe porque había oro de aluvión"5 (Entrevista, Bogotá, 26 de octubre de 2017). Por ejemplo, «el municipio de Vetas es fundado en el año de 1555 con el nombre de "Real Minero de Vetas" y, como su nombre lo indica, nace como mina de la Corona española» (Buitrago, 2012, p. 15). El campesinado que habita la zona de influencia de Santurbán cuenta con cuatrocientos años

Figura 1. Ubicación del páramo de Santurbán

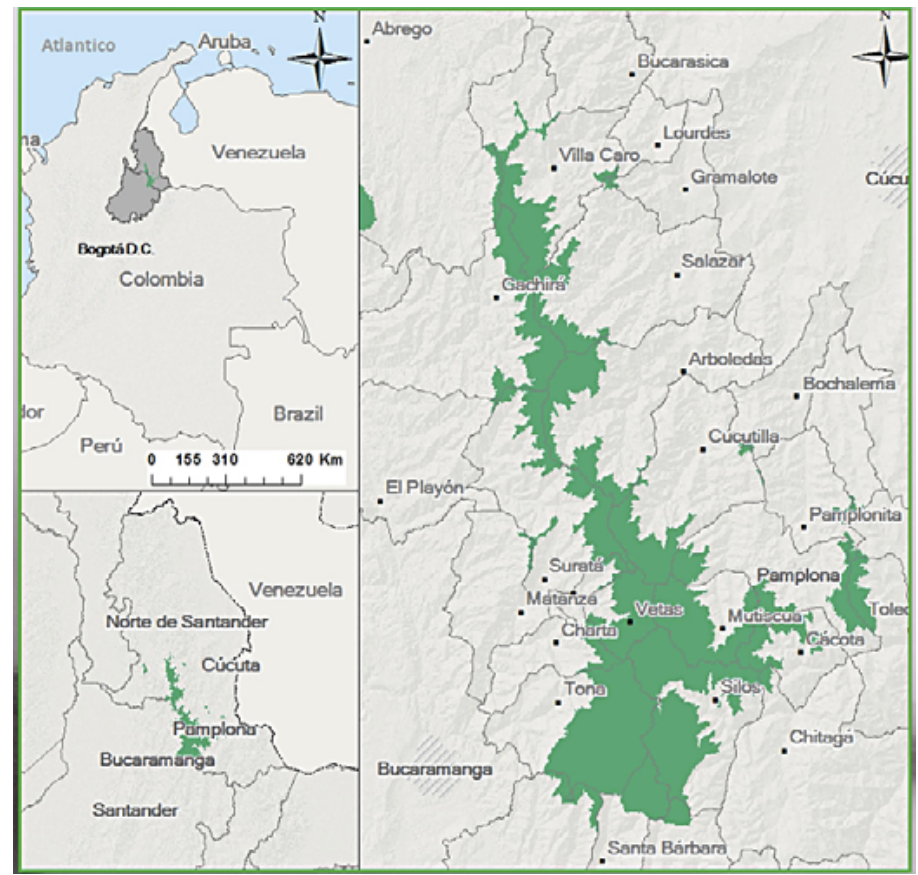

Fuente: Ministerio de Ambiente y Desarrollo Sostenible. 
de tradición aurífera y reconoce que sus creencias, la conformación de sus familias, las relaciones sociales y la dinámica cotidiana de los pueblos giran entorno a esta actividad a pequeña escala en su forma tradicional y artesanal. ${ }^{6}$

La minería a gran escala llegó al territorio en 1994 con la empresa Greystar Resources Ltda. (actualmente, Eco Oro), que se enfrentó con la actividad minera a pequeña escala, tanto en su forma de explotación como en las relaciones trabajo-familia. Por ejemplo, la minería a gran escala propuesta por Greystar se basa en la técnica de extracción a cielo abierto, la cual corresponde a la apertura de grandes tajos de montaña en forma de escalones gigantes para extraer los minerales en las zonas en las que se ha verificado la existencia de estos. Este tipo de extracción se realiza con grandes maquinarias con el fin de sacar la mayor cantidad de oro en el menor tiempo posible, lo cual no sucede con la minería a pequeña escala, que es menos tecnificada y por lo tanto menos eficaz. En cuanto a las relaciones trabajo-familia, la empresa de minería industrial mantiene una relación exclusivamente laboral con sus empleados, aspecto notablemente diferente a la minería de pequeña escala, la cual se basa en lazos de parentesco, es decir, los empleados normalmente tienen una relación familiar con los patrones. La minería industrial, además, sigue procedimientos burocráticos y normatividad estricta.

Cuando en el extractivismo se disputan fuerzas, esto desencadena múltiples conflictos por rupturas en las relaciones entre el ser humano y el entorno, creación de dependencia de las poblaciones con las empresas multinacionales, fractura de las relaciones sociales y modificación de las formas de vida. La llegada de Greystar al páramo representó un problema, cuando el 23 de diciembre del 2009, solicitó al Estado colombiano una licencia ambiental para realizar explotación aurífera a gran escala, a cielo abierto dentro del páramo de Santurbán. Dicho proyecto, denominado Angosturas, se localiza cerca de la quebrada del mismo nombre en el municipio de California. El proyecto a cielo abierto planteaba abrir un tajo de 220 hectáreas con una profundidad de 200 metros en la parte más alta de la montaña, de donde sale el oro. Según las cifras que presenta el estudio de impacto ambiental de la Greystar, el proyecto utilizaría 40000 kilos de cianuro y 230 toneladas de Ammonium Nitrate-Fuel Oil ${ }^{7}$ al día (https://www. elespectador.com/impreso/temadeldia/ articuloimpreso-241885-fiebre-del-orosanturban).

La magnitud de este proyecto generó preocupaciones sociales que llevaron a emprender acciones colectivas de ambientalistas y de mineros tradicionales. Las posturas de las poblaciones, construidas desde distintas perspectivas, entraron en conflicto por la diversidad de intereses implicados.

En la perspectiva de las sociabilidades $^{8}$ de la ciudadanía de Bucaramanga, la minería industrial es una amenaza al

discontinuos, normalmente alejados de los centros poblados principales. La expansión del fenómeno se caracteriza por transformación drástica del paisaje por deforestación, erosión y cambio en el curso de los ríos" (UNODC \& Gobierno de Colombia, 2016, pp. 19 y 117).

${ }^{6}$ En términos legales, la mineria tradicional es una actividad caracterizada por la larga duración que "debe cumplir con dos requisitos para que los mineros de hecho que lleven cierto tiempo realizando esta actividad tengan la posibilidad de legalizar su trabajo: 1) que los trabajos mineros se hayan adelantado en forma continua durante 5 años, y 2) una existencia minima de diez años anteriores a la vigencia de la Ley 1382 de 2010" (Defensoría del Pueblo, 2010). La minería artesanal, por su lado, se reduce al barequeo, definido como "el lavado de arenas por medios manuales sin ninguna ayuda de maquinaria o medios mecánicos y con el objeto de separar y recoger metales preciosos contenidos en dichas arenas" (Congreso de Colombia, 2001). En

\section{territorios 42-Especial}


$\Leftarrow$

las investigaciones socioambientales no existe claridad sobre la diferencia entre los dos términos y muchas veces se hace uso de ambos para referirse a un mismo tipo de minería, que es a pequeña escala, precaria y con bastante tiempo de existencia.

${ }^{7}$ Ammonium Nitrate Fuel Oil (ANFO) es un explosivo de alta potencia consistente en una mezcla de nitrato de amonio sólido y combustible derivado del petróleo (Kelso \& Choromokos, 1973).

${ }^{8}$ Sociabilidades se entiende aqui como los modos de interacción en la vida cotidiana y de las formas de agrupación permanente $o$ modos de asociación (Agulhon, 1988/1994, p. 194).

\section{territorias 42-Especial}

entorno natural del páramo, su ecosistema y los recursos que este ofrece. En Bucaramanga se conformó el Comité para la Defensa del Páramo de Santurbán aproximadamente en 2009 , en alianza con la Fundación Adán (Asociación Defensora de Animales), el Comité del Agua, la Escuela Agrocampesina de la Provincia de Soto, la Liga de Usuarios de Servicios Públicos, el Sindicato de Trabajadores de la Empresa Pública de Alcantarillado de Santander (Sintraempas) y el Sindicato de Trabajadores y Empleados de Servicios Públicos (Sintraemsdes). Así mismo, en dicho comité participó la Federación Nacional de Comerciantes (Fenalco) y políticos como el diputado Roberto Schmallbachs (Buitrago, 2012, p. 8). Este comité nació con el objetivo de hacer seguimiento al proyecto Angosturas de la empresa Greystar y rechazar socialmente los efectos del extractivismo a cielo abierto en la calidad del agua que surte a la ciudad de Bucaramanga y su área metropolitana. Con este objetivo, también se creó en 2011 el Movimiento Cívico Conciencia Ciudadana. Estas organizaciones sociales han captado la atención de la ciudadanía santandereana, específicamente bumanguesa, para realizar acciones como marchas, foros, reuniones y, por medio de la acción social colectiva, defender el agua de Santurbán.

(...) la primera lucha que se dio contra Eco Oro, nos permitió ganar a nivel nacional un espacio muy importante. Eso nos permite tener amigos y tener un poco de organizaciones no gubernamentales tanto nacionales como internacionales que aportan y apoyan el desarrollo de este tipo de gestiones en defensa del medio ambiente $(. .$.$) a nivel departamental tenemos$ el Comité del Páramo y en el Comité del Páramo convergen una serie de ejes y grupos ambientalistas y está hasta el sindicato del acueducto; hemos tenido bastante fortaleza en ese aspecto organizativo y a nivel nacional hemos encontrado organizaciones muy claves que nos han venido apoyando como Dejusticia, son las organizaciones que nos están llevando todos los procesos de demandas, de tutelas, de demandas que se han hecho ante la Corte Constitucional. Entonces ya hay una red que permite tener un poco más de confianza de que ya no es solamente nosotros ( $\mathrm{sic}$ ) ya es casi todo el país que se está levantando contra la gran minería (...) Parece que esa red de nuevas voluntades en defensa del medio ambiente es muy importante para el país y es lo que nos puede dar realmente el triunfo para que se cambie el modelo extractivo y se vuelva un modelo más pensando en el desarrollo industrial del país (Actor clave 6, Bucaramanga, 27 de julio de 2017).

Por el lado de las sociabilidades de Santurbán, los intereses corresponden a la búsqueda de condiciones de vida dignas, que promuevan oportunidades laborales derivadas de la minería y propendan por la mejora de la calidad de vida. Allí, la población divide sus posturas entre quienes ven en el proyecto de minería industrial una 
oportunidad para mejorar sus condiciones económicas y mantener una estabilidad laboral, y quienes lo encuentran problemático para la conservación del ambiente, la protección del agua, la tradición minera a pequeña escala y las dinámicas de la vida cotidiana.

En 2011, una parte importante de quienes habitan el territorio de Santurbán, especialmente de California, se inclinaron por el apoyo al proyecto Angosturas, y se opusieron a las acciones colectivas ambientalistas. Su postura respondió a varios factores: escasas alternativas de generación de ingreso diferentes a la minería industrial, el abandono por parte de las instituciones y la venta masiva de títulos mineros de pequeña escala a la empresa multinacional Greystar Resources. ${ }^{9}$ En primera medida, las necesidades de asistencia estatal y de programas para impulsar el desarrollo social configuraron en la empresa multinacional una figura paternalista capaz de solucionar los problemas más urgentes de las personas. Además, la venta de los terrenos con títulos mineros a la empresa a precios bajos trajo como consecuencia el tránsito de mineros independientes a empleados en la empresa minera. El proyecto Angosturas constituyó así la única salida económica posible.

el gobierno fue el que tuvo la culpa de que las multinacionales se metieran a esta región. El gobierno no le colaboró a los pequeños mineros, los alcaldes que estuvieron antes no le colaboraron a la pequeña minería, sino que llegó fulano y compró y nadie estuvo pendiente de toda esa negociación y la gente regaló, no sabía qué tenía, mucha gente durmiendo encima del oro y no sabía de la riqueza tan grande que tenían y los hijos de esos mineros que vendieron hoy en día pidiendo empleo (Actor clave 2, California, 23 de agosto de 2017).

A pesar de que la forma de extracción era totalmente distinta a la acostumbrada, para estos pobladores trabajar en la minería industrial era también una forma de continuar ejerciendo la labor que conocen y que les ha permitido la subsistencia por varias generaciones. El agua como recurso a defender no se encontraba dentro de su discurso, no porque no les preocupara, sino porque dentro del amplio panorama del conflicto, la subsistencia en el acontecer inmediato sobrepasaba la idea de una posible carencia de agua en un futuro "lejano". A esto se suma el peso de siglos de explotación sin afectación radical de las fuentes hídricas ni del ecosistema del páramo, lo que lleva al imaginario de la compatibilidad de ambos recursos: el oro y el agua. Además, el barequeo, como una de las formas más primitivas y masificadas de extracción aurífera transmitida de generación en generación, conecta la importancia de los dos recursos: el agua y el oro por coexistir en un mismo lugar, es decir, el río, que permite la subsistencia de las comunidades.

Aunque en el páramo de Santurbán gran parte de la población apoyaba el
${ }^{9}$ Los pobladores de Santurbán que tenian títulos mineros en el páramo los vendieron a la multinacional. territorios 42-Especial 
${ }^{10}$ La escala espacial es el "cociente entre el tamaño de un mapa y la distancia real o en terreno. También puede hacer referencia al detalle con el cual se describe o representa determinada información” (Rivera \& Rodriguez, 2011, p. 53). Esta escala es utilizada para medir el limite hasta donde los páramos y humedales pueden o no ser explotados.

11 "Las corporaciones autónomas regionales $y$ de desarrollo sostenible son entes corporativos de carácter público, integrados por las entidades territoriales, encargados por ley de administrar — dentro del área de su jurisdicción-el medio ambiente y los recursos naturales renovables, $y$ propender por el desarrollo sostenible del pais" (http:// www.minambiente.gov. co/index.php/component/ content/article/885-plantilla-areas-planeacion-yseguimiento-33).

\section{territarios 42-Especial}

proyecto minero a cielo abierto propuesto por Greystar, algunas personas eran críticas del mismo y se unieron a la voz de la población bumanguesa para defender el agua y el territorio, lo cual no significó una tarea fácil debido al contexto conflictivo; las personas temían participar de acciones ambientalistas debido a su dependencia al trabajo que ofrecía la multinacional: "aquí necesitamos muchos millones de personas porque por aquí habemos (sic) unos doscientos o trecientos... no alcanzamos a ser doscientos... pero por el páramo y el agua no hay más, porque los que están acomodados no pueden pelear" (Entrevista grupal, California, 23 de agosto de 2017). Aun así, la intensa movilización social de los grupos ambientalistas del área metropolitana de Bucaramanga y alguna población de Vetas y California por la defensa del páramo logró que el Ministerio de Ambiente, Vivienda y Desarrollo Territorial, mediante la Resolución 1015 de 2011, negara la licencia ambiental al proyecto Angostura de minería de oro de la empresa Greystar en el páramo de Santurbán en Santander. Dicha resolución es narrada por los ambientalistas como un logro relevante de su activismo.

Pero tal conquista no terminó allí. La insistente petición de que el páramo y su riqueza hídrica se respetaran, llevó a que el gobierno de Juan Manuel Santos propusiera en 2014 un proyecto de ley que buscaba la delimitación y protección de las zonas páramo en todo el país. En el artículo 202 del Plan Nacional de
Desarrollo 2010-2014 se menciona que los páramos deberían ser delimitados a escala 1:2500010 junto con los humedales. Las movilizaciones en contra del proyecto Angosturas en Santurbán y la presión de las empresas multinacionales por tener claridad acerca de las zonas explorables hicieron que este complejo fuera el primero en ser delimitado. Para esto, se pidió la elaboración de estudios técnicos a las corporaciones autónomas regionales ${ }^{11}$ con jurisdicción en el páramo: Corporación Autónoma Regional para la Defensa de la Meseta de Bucaramanga (CDMB) y Corporación Autónoma Regional de la Frontera Nororiental (Corponor) (Buitrago, 2016, p. 151).

Con base en dichos estudios, el páramo fue delimitado mediante Resolución 2090 de 19 de diciembre de 2014. Bajo esta normativa se "prohíbe las actividades de exploración y explotación de hidrocarburos y minerales, así como la construcción de refinerías de hidrocarburos en los páramos" (https://www. elespectador.com/noticias/politica/ una-ley-ajustada-proteger-paramos-yhumedales-de-colomb-articulo-606967). La delimitación de páramos puede ser entendida como

un intento de brindar mayor claridad tanto a las autoridades ambientales como a las empresas mineras sobre las áreas explotables y de silenciar a los ambientalistas, al facilitar así, sin tener en cuenta las complejidades, el establecimiento de los mínimos intocables 
que supuestamente garantizan la oferta hídrica (Buitrago, 2016, p. 146).

Esto significa un nuevo trabajo, aún más intenso para el ambientalismo, pues la división de la montaña en dos espacios geográficos y ambientales distintos, uno protegido y el otro no, ${ }^{12}$ abrió la posibilidad de desarrollar proyectos a gran escala por debajo de la línea de delimitación, pero no garantizó el cuidado de la fuente hídrica de Santurbán, la cual no depende exclusivamente de las lagunas, sino de la montaña como un complejo biodiverso y geográficamente indivisible. Para la población de Santurbán, la crítica de los proyectos mineros a gran escala, también representó un conflicto de gran impacto. Antes de la delimitación, las empresas transnacionales compraron la mayoría de sus títulos a las familias propietarias de minas con explotación a pequeña escala, lo que significó un choque por la pérdida de la tradición y la estabilidad económica. No obstante, después de la delimitación del páramo, se eliminó toda posibilidad de explotar las minas por encima de la línea y, en consecuencia, de llevar a cabo el proyecto Angosturas por parte de Greystar; en el caso de las personas que conservaron sus minas, venderlas dejó de ser una posibilidad, pues lo precios se volvieron irrisorios. El proceso de delimitación, en lugar de solucionar las tensiones y los conflictos ambientales en la zona, los aumentó y provocó desconfianza y preocupación por el futuro.
Como se puede ver, el conflicto socioambiental en el páramo de Santurbán es complejo. Los discursos de los actores sociales inmersos en él se enfrentan bajo dos premisas únicas: agua vs. oro. Sin embargo, la situación revela aspectos que van mucho más allá de la dicotomía "conservación/explotación”, que no pueden ser ignorados. Es importante reconocer que este conflicto juega un papel relevante en la reconfiguración de las representaciones de las poblaciones sobre el agua y el oro. La importancia del reconocimiento de lógicas de distinta naturaleza radica en que la asimetría entre estas implica desigualdades entre los diferentes actores relacionados con el páramo y define jerarquías en el acceso a los recursos naturales (Buitrago, 2016, p. 159).

En esta discusión hay que reiterar que en un mismo espacio geográfico se disputan múltiples territorialidades; el espacio es una construcción social y política influenciada por experiencias que no corresponden solo a quienes habitan el lugar, sino también a quienes tienen algún tipo de relación con el mismo. En este caso, por ejemplo, los habitantes de Bucaramanga, al ser los receptores del agua que proviene de Santurbán; las empresas multinacionales que están interesadas en la explotación de oro a gran escala en la zona, y el Estado en su responsabilidad de velar por los derechos de las poblaciones e impulsar el desarrollo y el crecimiento económico nacional. Esto implica una disputa de poderes por el dominio de los
12 Para ampliar esta información consultar el enlace: https://redjusticiaambientalcolombia.files. wordpress.com/2016/03/ res_2090_2014-santurban. $p d f$ territorios 42-Especial 


\section{territorias} 42-Especial recursos del páramo desde un punto de vista económico, político y de derechos.

\section{Reconfigurando las territorialidades y representaciones del agua y el oro}

Aunque la minería tradicional existe en Santurbán desde hace más de cuatro siglos, no es sino hasta el nuevo milenio que los conflictos por la minería a gran escala se hacen visibles. La crisis socioambiental surgida en 2011, movilizó intereses diversos en acciones colectivas tanto en los municipios mineros de Santurbán, como en la ciudad de Bucaramanga. Así mismo, fue un conflicto que moduló las representaciones del territorio como espacio de vida y recurso. El agua y el oro se convirtieron en elementos aparentemente opuestos, no porque naturalmente así sea, sino porque así lo decidieron los actores implicados en el conflicto.

De acuerdo con Francisco Sabatini (1996, p. 2), un mismo lugar, un mismo momento y los mismos recursos pueden involucrar diferentes actores. En el conflicto socioambiental en torno al páramo de Santurbán está en juego no solo la disputa de los habitantes del Área Metropolitana de Bucaramanga, de la población de Soto Norte, de la empresa extractora multinacional y del Estado por dos elementos de la naturaleza, sino también la construcción antropológica de los discursos. Como lo argumentó el psicoanalista Jaques Lacan (2007, p. 43), la realidad siempre es discursiva, es decir, que las formas de vida, la relación con los servicios ecosistémicos y las relaciones sociales, entre otros aspectos, están determinados por lo que narran los actores sociales.

Si bien existen distintas representaciones sociales respecto al entorno natural (unas que lo conciben como recurso o medio para lograr fines, y otras que lo conciben como espacio de vida o lugar de convivencia), las dinámicas de apropiación del mismo siempre traen consigo impactos socioambientales. Una lectura antropológica puede ayudar a entender que la construcción social de las territorialidades y el uso de los recursos naturales alude a un hecho simbólico y no meramente utilitario (Orellana, 1999b, p. 333).

Las entrevistas realizadas a actores clave tanto de Bucaramanga, como de los municipios mineros de Santurbán ofrecen diferentes lecturas de las representaciones del páramo y sus características naturales. En una lectura anterior al conflicto de 2011, se evidencia en gran medida para las sociabilidades de Vetas y California, y en menor medida para las sociabilidades de Bucaramanga, una percepción del páramo como espacio vital. Para los pobladores de Santurbán, habitar municipios como Vetas o California, determina la construcción del territorio como un lugar en donde se desarrollan actividades de trabajo, estudio y recreación, donde se crean hábitos propios de la relación cercana con la naturaleza que rodea dichas actividades. De acuerdo con los participantes de Santurbán, se puede percibir una representación del páramo, 
el agua y el oro de cuidado, protección, producción y reproducción.

Yo nací aquí y mi familia ha vivido aquí desde muchas generaciones atrás. Para mí el páramo, el agua que produce, las plantas que tiene, es algo que debo cuidar, que siempre he cuidado, a pesar de que mi trabajo sea la minería. Yo veo el páramo como algo que me da y yo también le doy, como un lugar en el que vivo y en el que me relaciono, es el lugar en el que está toda mi vida (Actor clave 2, California, 23 de agosto de 2017).

En el caso de Bucaramanga, pese a no tener una interacción directa y cotidiana con el páramo, las representaciones de Santurbán como espacio vital también se perciben. La riqueza natural de Santurbán es configurada geográfica y simbólicamente como un territorio que empieza en las lagunas y termina en la ciudad. El agua, como conductor de la relación del páramo con la ciudadanía bumanguesa, determina la forma en la que las personas lo entienden. Como afirma una de las personas entrevistadas: "Mi relación con el páramo existe porque de Santurbán viene el agua que yo consumo y que he consumido durante toda la vida" (Actor clave 1 , Bucaramanga, 26 de Julio de 2017). Es decir, el valor de Santurbán radica en la vitalidad, el ambiente y el clima, y en esa medida, la modulación de las relaciones sociales de quienes lo habitan o se benefician de sus afluentes hídricos.
Sin embargo, la existencia de una amenaza tangible a la riqueza del páramo de Santurbán transforma las territorialidades. La posibilidad de que la extracción a gran escala de oro acabe con el recurso hídrico para Bucaramanga trae la necesidad de cuestionar la influencia de este territorio para las poblaciones, no solo en términos de minería para sus habitantes, sino en términos de fuente vital. A pesar de que gran parte de la sociedad santandereana no se percata de la relación del páramo con su cotidianidad, las acciones colectivas llevan a la concientización del territorio como un espacio de gran riqueza, único en el mundo e imprescindible para la vida humana. Como lo afirma uno de los entrevistados:

Mi relación con Santurbán, con la montaña, con los municipios, con sus habitantes es mayor ahora que la que tenía hace diez años, pues desde Bucaramanga no somos conscientes de la importancia de Santurbán sino desde hace ocho años, ¿por qué? Porque hace ocho años fue cuando quedó planteada la amenaza al agua de Bucaramanga por parte de proyecto Angosturas. En ese momento se organizan los diferentes movimientos para defender el agua y trabajar por la defensa del páramo (Actor clave 1, Bucaramanga, 26 de julio de 2017).

Las territorialidades en torno al páramo se reconstruyen en medio de disputas sociales complejas. Debido a la intención territorias 42-Especial 
de la multinacional Greystar de realizar minería a cielo abierto, se configuró la estigmatización y la confrontación entre intereses de población de un lado y de otro. El rechazo a la extracción de oro y la protección del agua de páramo determinaron el discurso de las acciones colectivas mayoritariamente del área metropolitana de Bucaramanga aunque también de algunos habitantes de los municipios de Vetas y California, que orientaron sus acciones hacia el apoyo del ambientalismo. Marchas masivas, foros y reuniones apoyadas por movimientos sociales e instituciones con posicionamiento departamental y nacional exigieron la protección del recurso hídrico de Santurbán y la eliminación de todo tipo de extracción minera que atentase contra el medio ambiente.

En dicha dinámica, el rechazo rotundo a la minería se extiende, y se construye la percepción del minero como "personas que solo piensan en sus intereses (...) que quieren enriquecerse rápido sin pensar en el medio ambiente" (Buitrago, 2012, p. 10), y como los mismos habitantes mineros dicen: "nos trataban como asesinos por apoyar la minería industrial" (Entrevista grupal, California, 23 de agosto de 2017). Si bien es cierto que el extractivismo industrial trae efectos que dificultan la convivencia en los pueblos, el apoyo de la población del páramo a este tipo de extracción corresponde a la preocupación no solo por el aprovisionamiento de agua, sino también por el sustento de las familias, el crecimiento económico de los pueblos y las oportunidades para mejorar la calidad de vida.

La minería de Santurbán, específicamente de los municipios de Vetas y California es histórica y determina la vida, las costumbres y la cultura de las poblaciones que la desempeñan. Su tipo de explotación, al tener tanto tiempo de existencia y caracterizarse por la poca tecnificación y maquinaria para desarrollarla a gran escala, recibe el nombre de tradicional o artesanal. Para sus habitantes, su trabajo corresponde a una tradición, hace parte de la configuración y transmisión de saberes y de la identidad de las familias. Las acciones colectivas ambientalistas son percibidas por ellos como una amenaza para la subsistencia de la población de Vetas y California, lo que los lleva a cuestionar la preocupación de la población bumanguesa por la defensa del agua y a resaltar su defensa del territorio a partir de su vivencia cotidiana dentro de él:

Nosotros sí lo hemos cuidado toda la vida [el páramo], vea la gente de Bucaramanga... ahorita es que la gente está especulando y diciendo cosas... ni conocen ni saben qué hay allá y vea nosotros toda la vida, porque mire yo tengo sesenta años, quién ha cuidado todos esos nacimientos de agua... nosotros los californianos y los del páramo de Santurbán (Actor clave 2, California, 23 de agosto de 2017).

En este punto, la disputa empieza a reconfigurar las representaciones del 
páramo, el agua y la riqueza mineral. El espacio vital pasa a ser visto con un sentido utilitarista, de "recursos" naturales; esto sucede con tanta rapidez, que la transición parece imperceptible. Santurbán pasa a ser nombrado como lugar que ofrece agua para vivir u oro para trabajar, lo que reduce el acontecer de sus pobladores a una relación de explotación y aprovechamiento más que a una relación cultural, antropológica y de construcción social de territorialidades. La popularización de la consigna "agua vs. oro" divide a las poblaciones porque las separa en dos únicas posturas: proagua o prooro.

Esta división, clasificada por René Orellana (1999a): "la naturaleza entendida como recurso natural" y "la naturaleza como un espacio de vida" (p. 101), desencadena conflictos, pues las territorialidades se superponen por las representaciones disímiles del agua y el oro entre distintos actores. Por una parte, las empresas extractivas y del Estado ven el territorio con un interés específicamente económico: el oro que compone sus montañas significa la posibilidad de posicionamiento en el mercado mundial, que sitúa al agua en un segundo plano. Por parte de las comunidades de Bucaramanga, Santurbán significa agua, no como un recurso a explotar, sino como símbolo de vida, el cual baja de las montañas, recibe un tratamiento por parte del acueducto de la ciudad y llega a los hogares para su consumo diario. En el caso de las comunidades que habitan los municipios de Vetas y California, el agua del páramo es parte importante de su identidad: convivir con el clima paramoso, apreciar el sistema hídrico como una riqueza única en el mundo y beber el agua directamente de los nacimientos que existen en los territorios ${ }^{13}$ convierten al agua no en un recurso, sino en parte de su espacio vital. Israel Sandre y Daniel Murillo (2008) afirman que "el agua para los seres humanos no solo representa una necesidad básica para la sobrevivencia, más bien se puede considerar un factor clave en el desarrollo de la humanidad en sus distintos contextos geográficos y climáticos" (p. 7).

El oro, por su parte, comparte importancia con el agua, pues es visto no como recurso para el enriquecimiento personal, sino como medio de subsistencia comunitaria y base de las relaciones sociales, es decir, un recurso tan importante como el agua. $\mathrm{Al}$ respecto, vale decir que proceder de Santurbán tiene una fuerte relación con el sentido de pertenencia por el hecho de ser minero, de convivir con un espacio rico en oro y de crear en torno a esta práctica relaciones de solidaridad en las comunidades; por ejemplo, permitir el galafardeo ${ }^{14}$ como actividad tradicional, hacer minería a pequeña escala como negocio familiar y comunitario, así como practicar el barequeo ${ }^{15}$ son actividades solidarias donde el pueblo se acompaña en su subsistencia cotidiana. Como se puede leer en el testimonio de dos mujeres californianas: "la
${ }^{13}$ Cuando se está llegando a Vetas y a California, en el camino son visibles pequeñas nacientes de agua clara y cristalina, que las personas beben sin que esta requiera un tratamiento sanitario.

${ }^{14}$ El galafardeo consiste en ingresar de manera informal a las minas para, por medio de herramientas rudimentarias como la pica y la pala, buscar oro. Esta práctica, por no ser formal, no tiene garantias laborales, de salud ocupacional ni le garantiza a quienes ingresan a las minas que van a tener hallazgos $f a-$ vorables. Es una práctica tradicional en los municipios auriferos, aunque es ilegal desde la perspectiva normativa.

${ }^{15}$ El barequeo consiste en el lavado de arenas que se encuentran en los ríos por medios manuales sin ninguna ayuda de maquinaria o medios mecánicos y con el objeto de separar $y$ recoger metales preciosos.

\section{territarios 42-Especial}


economía nuestra era mejor cuando estaba la minería artesanal, vivíamos mejor, se movía más el flujo económico (...) si hoy su mina daba, daba para todo el mundo, no solo para el que era dueño" (Actor clave 3, California, 23 de agosto de 2017).

habemos (sic) mujeres cabeza de hogar que no tenemos terrenos, no tenemos nada y a veces dependemos de esas familias que tienen ese terreno, ¿̨en qué sentido dependemos...? que si hay un trabajo o algo uno llega ahí, así sea cocinando, ayudándoles a los obreros, entonces ellos lo dejan entrar a uno a la mina o ellos le sacan a uno una maleta (Actor clave 2, California, 23 de agosto de 2017).

El barequeo explica en gran medida por qué el oro comparte su importancia con el agua para estas comunidades. La explotación de oro en pequeñas minas produce desechos que son arrojados al río; en el curso de esta fuente hídrica, otras personas (mayoritariamente mujeres) barequean y recogen oro. El agua en este ejercicio se convierte en conductor de oro y en ese sentido adquiere un valor trascendental para la subsistencia económica de las comunidades, lo cual indica que para las personas de Santurbán la disyuntiva "agua vs. oro" no es clara y las exigencias de la población de la meseta de Bucaramanga parecen inconcebibles.

Ahora bien, aunque los pobladores del páramo gozan del conocimiento de su propia historia y tradición, la llegada del extractivismo industrial que se ofrece $\mathrm{co}^{-}$ mo la opción más rápida para el desarrollo "hace especial hincapié en la reducción de las desigualdades y de la pobreza extrema, pero no contempla los costos ni los riesgos socioambientales que la extracción produce tanto para la población local, como para las futuras generaciones" (Gobel, Góngora-Mera \& Ulloa, 2014, p. 15). Para algunas personas de Santurbán, el discurso desarrollista, es decir, aquel que promete mejorar su calidad de vida a partir de la participación activa en el mercado mundial, no es evidente en la práctica para las comunidades, pues no se evidencia un equilibrio entre la explotación de los recursos a gran escala y la conservación del medio ambiente que les permita apoyar el extractivismo con tranquilidad:

Si uno mira a nivel internacional los organismos que defienden todo el tema ambiental son opositores a un daño ecológico, no a un desarrollo, porque que maravilloso sería que nos dijeran, no, es que vamos a hacer un gran desarrollo pero no le vamos a causar ni un solo impacto al tema ambiental, eso tendría que ser la fórmula mágica, cómo hacer para que se cree, se innove, se investigue una forma en la que usted pueda sacar un recurso mineral sin causar daño al medio ambiente, pero eso es errado, el que diga eso está diciendo mentiras porque usted necesariamente va a causar impactos (...) lo peor es que ni siquiera el desarrollo lo van a hacer en California, a nosotros nos 
van a aislar (Actor clave 3, California, 23 de agosto de 2017).

Igual lo confirma el movimiento ambientalista de Bucaramanga al identificar una serie de problemáticas adicionales a las ambientales para el desarrollo de las comunidades en los proyectos extractivistas de gran escala:

Hay muestras de que se aumentan los niveles de delincuencia, los niveles de prostitución, de madres solteras porque es muy obvio, porque vienen los extranjeros con sus caras bonitas, conquistan nuestras mujeres, las embarazan y luego se van y queda la ruptura de los núcleos familiares (...) además, en el ambiente se presenta acidificación de aguas, ruptura de acuíferos, disminución del caudal amenazando el caudal ecológico de los ríos, expulsión de gases nitrosos a través de la explotación causantes de lluvias ácidas, material particulado por montones causante de cáncer en todas las zonas de minería en el mundo, (...) expulsión de metales pesados por sobre el agua, 3,8\% de regalías, 98 exenciones tributarias, ${ }^{16}$ desaparición de las especies endémicas tanto de flora y de fauna en el ecosistema, etc. (Actor clave 4, Bucaramanga, 09 de agosto de 2017).

Es decir, el conflicto no solo se limita a una disputa por "agua u oro", consiste en efectos mucho más dramáticos para las poblaciones como la polarización dentro del territorio y la confrontación de intereses como lo muestra el siguiente testimonio: nos tienen partidos el mismo gobierno, ¿cómo el gobierno le da el campo a las multinacionales y al pobre colombiano que está llevado no lo ayuda? Aquí lo que tenía que hacer con los pequeños mineros, los mineros tradicionales es darle un aporte (Actor clave 2, California, 23 de agosto de 2017).

Las empresas extractivas a gran escala establecen relaciones con los poderes públicos que los convierten en funcionales a las realidades y políticas neoliberales (Sánchez, 2016, p. 16). Entran a los territorios ofreciendo promesas y beneficios a las poblaciones, supliendo en parte las obligaciones estatales, lo cual se convierte en estrategia para imponer control sobre el territorio, para explotarlo. Estos emporios sectorizan el mundo de acuerdo con su portafolio de bienes, servicios y mercancías (Wallerstein, 1979). Como anota Guerrero (1999) "en las relaciones conflictivas siempre se involucra una intencionalidad de poder que pretende ganar el control sobre los objetos, los recursos, las posturas políticas, y de influir en el comportamiento del otro en cierta dirección" (p. 39). Ofrecer la idea del compromiso de la empresa privada con las comunidades hace parte del devenir de proyectos extractivos en países donde la mano interventora del Estado solo es visible en la normatividad y la fuerza pública, y poco en el diario vivir de las poblaciones que interactúan con el territorio a explotar. Como afirma una mujer entrevistada en California:
${ }^{16}$ Las exenciones tributarias son "situaciones excepcionales previstas en disposiciones normativas con rango de ley por las que, aun a pesar de realizarse el becho imponible, no nace la obligación tributaria. Las exenciones tributarias pueden ser: 1) objetivas, atendiendo a objetivos de tipo socioeconómico; 2) subjetivas atendiendo a la condición del sujeto pasivo, y 3) técnicas previstas para evitar dobles imposiciones" (bttp:// www.enciclopedia-juridica. com/d/exenciones-tributarias/exenciones-tributarias. $\mathrm{htm}$ ).

\section{territarias 42-Especial}

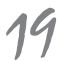


17 El Escuadrón Móvil Antidisturbios (ESMAD) es una unidad especial de la Dirección de Seguridad Ciudadana de la Policia Nacional de Colombia, cuya misión es el control de disturbios (principalmente en manifestaciones sociales), con el fin de restablecer el orden.

18 Aqui se entiende por nación el conjunto de personas que tienen en común una lengua, una historia y una cultura en un territorio determinado (pais). El Estado por su lado se refiere a la organización politica que integra a una población en un territorio y tiene autoridad sobre la misma.

\section{territarias 42-Especial}

tenemos un gobierno encima que va a decir es que si usted hoy se opone a esa minería yo voy y le mando al ESMAD ${ }^{17}$ para que calmen el brío y dejen de estar jodiendo tanto por algo que va porque va por encima de quien sea $(\ldots)$ si se oponen [la población] $\mathrm{y}$ se han visto marchas $\mathrm{y}$ se ha visto todo $\mathrm{y}$ como le digo lo que el gobierno ha hecho es mandar el ESMAD, la fuerza pública a que calle la boca (Actor clave 3, California, 23 de agosto de 2017).

De manera que una de las estrategias de Greystar en Santurbán fue la apuesta social, la cual incluye desde el año 2005 diversos programas sociales, que iniciaron con inversiones de 20 millones de pesos y aumentaron cada año hasta llegar a tener un valor de 800 millones de pesos en 2011. El apoyo al deporte y la recreación con el desarrollo de olimpiadas, clases de danza y teatro, mantenimiento de vías, donación de instrumentos quirúrgicos para el hospital local y la promoción del emprendimiento con créditos para generación de empresas fueron algunos de los proyectos de la compañía en el territorio. La técnica de poder que llega a gestionarse en este conflicto, propia del extractivismo, adquiere una forma sutil, flexible e inteligente, que escapa a toda visibilidad. Según Byung-Chul Han (2014), "el sujeto sometido no es siquiera consciente de su sometimiento". Las empresas transnacionales estimulan la creación de necesidades para generar dependencia en las poblaciones; se esfuerza por generar sentimientos como el agradecimiento y la lealtad, explotarlos, para de esa forma, seducir y convencer.

La favorabilidad de las comunidades es su principal objetivo, pues de esta forma facilita la aprobación de las propuestas de minería industrial por parte del gobierno, quien es en última instancia que puede decidir sobre el uso del subsuelo nacional de acuerdo con la Ley 685 de 2001, según la cual el subsuelo es propiedad del Estado y no de la nación ${ }^{18}$ (Fierro, 2012). De este modo, el Estado limita su acción al otorgamiento y fiscalización de contratos de concesión y a promover la inversión privada extranjera y nacional para la exploración y explotación. Ante esta situación, la principal herramienta que tienen las poblaciones del área de influencia directa e indirecta para que su posición frente a los proyectos extractivos sea escuchada es la acción colectiva.

Sin duda, la intervención externa de empresas de extracción a gran escala resignifica la relación de las poblaciones con el territorio (las territorialidades), así como las representaciones del agua, el oro y el páramo en sí. Las entrevistas realizadas a los actores involucrados en el conflicto sobre dichos aspectos evidencian un giro en las representaciones sociales del agua y el oro hacia su percepción como "recursos": es el caso de la relación de las comunidades auríferas con el agua del páramo de Santurbán. La disputa entre la prevalencia de un recurso u otro en el conflicto socioambiental en referencia 
lleva a las comunidades a preguntarse por la importancia de los mismos en sus vidas. Histórica y culturalmente, el sistema hídrico no significa únicamente producción del líquido vital, sino también un espacio sagrado. Así lo afirman las personas de California, quienes hablan de haber visitado las lagunas no más de dos veces en su vida (porque la presencia humana es una intromisión al sistema natural del páramo) y solo como un ejercicio de purificación y limpieza de cuerpo y alma, práctica heredada de los abuelos: "la gente de acá que casi no va a las lagunas, por lo general donde están las lagunas eso es como sagrado y por eso la gente no va" (Actor clave 7, Vetas, 10 de abril de 2018). Sin embargo, la importancia del agua y el páramo que la produce se ha transformado en un recurso que tiene dueño, alrededor del cual se tejen disputas sociales.

Este ejemplo evidencia la manera en la que este conflicto reconfigura y otorga a elementos como el agua y el oro valores que se oponen a su significación cultural y antropológica. Aquí, aunque algunos actores tienen una representación de la naturaleza como espacio vital, es necesario decir que desde el momento en que el conflicto se configura por intereses de aprovechamiento y propiedad, estos son resignificados y convertidos en recursos en disputa, que dependen de las presiones que definen las decisiones del Estado.

A pesar de que finalmente Greystar no logró explotar el páramo de Santurbán a gran escala, la delimitación de este y los hechos posteriores emergen de la discusión planteada, en la que el agua y el oro son una representación reducida de conflictos más complejos en este contexto geográfico. La dualidad entre estos dos elementos de la naturaleza se enmarca en un planteamiento extractivista en el que se pierde de vista la lectura antropológica de las sociabilidades y se plantea la naturaleza desde un punto de vista mercantilista, desconociendo su valor y trascendencia simbólica.

\section{Conclusiones}

En el conflicto socioambiental desencadenado por la propuesta extractivista a gran escala de Greystar en Santurbán se pueden identificar distintos puntos de vista que están ligados a la relación de los actores sociales con el páramo y su medio natural. Esta relación es descrita como territorialidades, las cuales se construyen y transforman constantemente a partir de las experiencias con el territorio, ya sea de forma directa o indirecta. Con la presencia de la empresa canadiense Greystar en Santurbán y su interés específicamente económico en el oro del páramo, las personas de los municipios de Vetas y California, así como las provenientes de Bucaramanga empezaron a cuestionar la importancia del agua y el oro en su vida cotidiana. La población de Santurbán, por un lado, encuentra estos dos elementos como vitales. El uno no excluye al otro, sino que coexisten, pues si bien el agua es territarios 42-Especial 
fundamental para la existencia, el oro rige la economía, las tradiciones y la cultura de los pueblos. Este elemento ha permitido la existencia de las comunidades de Santurbán durante más de cuatro siglos.

Por el lado de la población bumanguesa, la representación social del agua se relaciona con la vida y la del oro, con la contaminación. Si bien es curioso que antes de 2009 la población bumanguesa no dimensionaba la importancia del páramo Santurbán para la ciudad, es a partir de las intenciones extractivas de Greystar que este territorio cobra sentido en la cotidianidad, pues sin el agua que este produce, la ciudad de Bucaramanga tendría muchos problemas para subsistir. De este modo se configuró el discurso de las acciones colectivas de 2011 , en las cuales se manifestó el rechazo a la minería de gran escala a partir de la dualidad agua vs. oro. Esto generó una serie de conflictos entre las poblaciones de Santurbán y Bucaramanga pues se consideró que las defensas de los unos implicaban el ataque a los otros; por ejemplo, que la defensa del agua era amenaza a la pequeña minería o que la defensa de la minería era amenaza a la conservación del agua.

La presencia de la empresa transnacional desencadenó conflictos antes inexistentes entre dos poblaciones vecinas que se habían beneficiado del páramo históricamente. En un primer momento las comunidades de Bucaramanga y Santurbán reflexionaron sobre la importancia del oro y el agua en sus vidas, pero las tensiones producidas por la superposición de las territorialidades y las representaciones sociales dispares en torno al páramo dilataron el conflicto al punto de colocar al agua y al oro como dos recursos en disputa. Santurbán pasó a ser reconocido como fuente de agua para vivir y oro para trabajar.

En este conflicto, el Estado se distanció del papel de mediador. Por el contrario, su ausencia facilitó la entrada de la compañía transnacional para seducir y convencer a las comunidades de los beneficios de la minería a gran escala, perjudicando de manera importante a la minería artesanal como práctica con un gran valor cultural e identitario. El Estado era visible únicamente a través de la presencia de la fuerza pública. Por esto, algunas personas de Santurbán decidieron unirse a los grupos ambientalistas, pues encontraron en la acción colectiva la mejor vía para ser escuchados. Este conflicto evidencia que las comunidades de Santurbán se encuentran en una desprotección estatal persistente. Si bien el interés de los grupos ambientalistas por defender el agua confronta la perspectiva de la población minera de Santurbán, las acciones colectivas han permitido que tanto el Estado como la academia presten mayor atención a las comunidades y las problemáticas que las afectan.

Este artículo es producto de ese interés académico por conocer el conflicto y analizarlo desde su complejidad antropológica y cultural, pues devela justamente una evolución de la percepción del territorio 
y sus "recursos" y resalta jerarquías entre los distintos grupos sociales basadas en las territorialidades y las representaciones sociales superpuestas. Este texto expone la necesidad de continuar explorando las territorialidades y las representaciones del agua y del oro en la vida y la tradición de las comunidades que habitan el páramo, pues estas están en resignificación constante, por lo cual, la evolución del conflicto puede traer transformaciones de las mismas que vale la pena analizar.

Finalmente, la tensión que se vivió especialmente durante 2011 es una experiencia que marcó el desarrollo de conflictos posteriores con respecto a la delimitación normativa de los páramos y la "minería responsable" como nueva propuesta de extractivismo a gran escala. Estos son temas que merecen ser ampliados para aportar al entendimiento de la problemática vigente y de situaciones similares en otros lugares del país y del mundo.

\section{Referencias}

Acosta, A. (2009). La maldición de la abundancia. Quito: Ediciones Abya-Yala.

Agulhon, M. (1988/1994). Historia vagabunda: etnología y politica en la Francia contemporánea. México D.F: Instituto de Investigaciones José María Mora.

Bobbio, N. Matteucci, N., \& Pasquino, G. (1991). Diccionario de politica. México: Siglo XXI Editores.
Bourdieu, P., \& Wacquant, J. (1995). Respuestas: Por una antropología reflexiva. México: Grijalbo.

Buitrago, E. (2012). Entre el agua y el oro: tensiones y reconfiguraciones territoriales en el municipio de Vetas, Santander, Colombia. (Tesis de pregrado, Universidad Nacional de Colombia, Bogotá).

Buitrago, E. (2016). Limitaciones y delimitaciones de los páramos en una Colombia posacuerdo. En A. Ulloa \& S. Coronado (Comp.), Extractivismos y posconflicto en Colombia: retos para la paz territorial (pp. 142-159). Bogotá: Universidad Nacional de Colombia (UNAL) y Centro de Investigación y Educación Popular (CINEP).

Castro-Gómez, S. (2015). Revoluciones sin sujeto: Slavoj Zizek y la critica del historicismo posmoderno. Bogotá: Ediciones Akal.

Congreso de Colombia. (15, agosto, 2001). Por la cual se expide el Código de Minas y se dictan otras disposiciones. [Ley 685 de 2001]. DO: 44.545. Recuperado de https://www.minambiente.gov. co/images/normativa/leyes/2001/ ley_0685_2001.pdf

Defensoría del pueblo. (2010). La minería de hecho en Colombia. Bogotá: Defensoría del Pueblo. Recuperado de http://www2.congreso.gob.pe/sicr/ cendocbib/con4_uibd.nsf/F11B78 4C597AC0F005257A310058CA31 /\%24FILE/La-miner\%C3\%ADa-dehecho-en-Colombia.pdf tersitarios 42-Especial 


\section{territarias 42-Especial} 24
Dematteis, G., \& Governa, F. (2005). Territorio y territorialidad en el desarrollo local. La contribución del modelo slot. Boletin de la AGEN, (39), 31-58.

Fernández, B. (2005). Movimientos socioterritoriales y movimientos socioespaciales. Contribución teórica para una lectura geográfica de los movimientos sociales. Observatorio Social de América Latina (Clacso), 16. Recuperado de https://www.researchgate. net/publication/267217667_Movimientos_socioterritoriales_y_movimientos_socioespaciales_Contribucion_teorica_para_una_lectura_geografica_de_los_movimientos_sociales

Fierro, J. (2012). Politicas mineras en Colombia. Bogotá: Ilsa.

Franky, C., \& Mahecha, D. (2000). La territorialidad entre lospueblos de tradición nómada del noroeste amazónico colombiano. En J. J. Vieco, C. E. Franky \& J. A. Echeverri (Eds.), Territorialidad indigena y ordenamiento en la Amazonia (pp. 183-210). Bogotá: Editorial Unibiblos.

Gobel, B., Góngora-Mera, M., \& Ulloa, A. (1979). Desigualdades socioambientales en América Latina. Bogotá: Universidad Nacional de Colombia.

Guattari, F., \& Rolnik, S. (2006). Micropolitica. Cartografias del deseo. Madrid: Traficantes de Sueños.

Gudynas, E. (2015). Extractivismos. Ecología, economía y politica de un modo de entender el desarrollo y la naturaleza. Bolivia: CEDIB.
Guerrero, P. (1999). Aproximaciones conceptuales y metodológicas al conflicto social. En P. Ortíz (Comp.), Comunidades y conflictos socioambientales: experiencias y desafíos en América Latina (pp. 37-41). Quito: Ediciones Abya-Yala.

Han, B. (2014). Psicopolitica. Barcelona: Herder editorial.

Kelso, J., \& Choromokos, J. (1973). Ammonium Nitrate/Fuel Oil Explosives. The Military Engineer, 65(425), 177-180. Lacan, J. (2007). El seminario. Libro 20. Buenos Aires: Paidós.

Melucci, A. (2010). Acción colectiva, vida cotidiana y democracia. México D.F.: Centro de Estudios Sociológicos.

Montañez, G. \& Delgado, O. (1998). Espacio, territorio y región: conceptos básicos para un proyecto nacional. Cuadernos de Geografia, 7(1-2), 121-134.

Orellana, R. (1999a). Aproximaciones a un marco teórico para la comprensión y el manejo de los conflictos socioambientales. En P. Ortíz (Comp.), Comunidades y conflictos socioambientales: experiencias y desafíos en América Latina (pp. 90-104). Quito: Abya-Yala.

Orellana, R. (1999b). Conflictos... ¿sociales, ambientales, socioambientales? Conflictos y controversias en la definición de conceptos. En P. Ortíz (Comp.), Comunidades y conflictos socioambientales: experiencias y desafíos en América Latina (pp. 328-371). Quito: Ediciones Abya-Yala. 
Quiroga, C. (2016). Varias caras de un incierto posconflicto. Entre la ilegalidad y la legalidad de la minería a pequeña escala. En A. Ulloa \& S. Coronado (Comp.), Extractivismos y posconflicto en Colombia: retos para la paz territorial (pp. 237-260). Bogotá: Universidad Nacional de Colombia (UNAL) y Centro de Investigación y Educación Popular (CINEP).

Raffestin, C. (2011). Por una geografía del poder. Tr. Yanga Villagómez. Michoacán: El Colegio de Michoacán.

Rivera, D., \& Rodríguez, C. (2011). Guía divulgativa de criterios para la delimitación de páramos de Colombia. Bogotá: Ministerio de Ambiente, Vivienda y Desarrollo Territorial e Instituto de Investigación de Recursos Biológicos Alexander von Humboldt.

Rodríguez, D. (2010). Territorio y territorialidad. Nueva categoría de análisis y desarrollo didáctico de la Geografía. Uni-pluri/versidad, 10(3), 1-11.

Sabatini, F. (1996). Conflictos por externalidades y conflictos por el control de los recursos ambientales. Santiago de Chile: Mimeo.

Sánchez, R. (2016). Prólogo. El neoextractivismo: la caldera del diablo. En A. Ulloa \& S. Coronado (Comps.),
Extractivismos y posconflicto en Colombia: retos para la paz territorial (pp. 11-22). Bogotá: Universidad Nacional de Colombia (UNAL) y Centro de Investigación y Educación Popular (CINEP).

Sandre, I., \& Murillo, D. (Eds.). (2008). Agua y diversidad cultural en México. Montevideo: PHI-LAC y Unesco.

Torres, V. (2005). Aprendiendo de los conflictos: experiencias metodológicas de manejo de conflictos socioambientales en Ecuador. Quitó: Plataforma de Acuerdos Socioambientales.

Ulloa, A., \& Coronado, S. (2016). Extractivismos y posconflicto en Colombia: retos para la paz territorial. Bogotá: Universidad Nacional de Colombia y Centro de Investigación y Educación Popular.

UNODC y Gobierno de Colombia. (2016). Explotación de oro de aluvión Evidencias a partir de percepción remota. Bogotá: UNODC y Gobierno de Colombia.

Valderrama, E. (1948). Real de Minas de Bucaramanga. Bucaramanga: El libro total.

Wallerstein, I. (1979). El moderno sistema mundial (Volúmen III). Buenos Aires: Siglo XXI Editores. territarias 42-Especial 